\title{
Spontaneous chronic subdural hematoma in a young male patient: case report
}

\author{
Luis Rafael Moscote-Salazar ${ }^{1}$, Hernando Raphael Alvis-Miranda ${ }^{2}$, \\ Willen Calderón-Miranda ${ }^{3}$, Gabriel Alcala-Cerra ${ }^{1}$, \\ Andres M. Rubiano ${ }^{4}$ \\ ${ }^{1}$ Neurosurgeon, Universidad de Cartagena, Colombia \\ ${ }^{2}$ Physician, Universidad de Cartagena, Colombia \\ ${ }^{3}$ Physician, Universidad de Magdalena, Colombia \\ ${ }^{4}$ Neurosurgeon, Hospital Universitario de Neiva, Colombia
}

\begin{abstract}
The chronic subdural hematoma is a common pathology in elderly patients. There is usually a history of head trauma. The diagnosis of chronic subdural hematomas in young patients is very rare and few cases have been reported in the literature. The authors present a case of a patient of 16 years old who presented headache of two months of evolution, which was conducted by tomography diagnosis of chronic subdural hematoma. The patient had no history of mild trauma. Surgical management was performed, showing a satisfactory evolution.
\end{abstract}

Key words: Chronic subdural hematoma, spontaneous, Headache, young.

\section{Introduction}

Chronic subdural hematoma (CSH) was described in 1857 by Virchow, who was based in the hematic origin, and then named "internal hemorrhagic paquimeningitis." $\mathrm{CSH}$ is basically a blood collection located under the dural membrane and which is mainly characterized by the presence of capsule evolving the collection; generally occurring in elderly people, (1) Currently is observed an increase in the frequency of occurrence of $\mathrm{CSH}$, probably due to increased life expectancy and the progress experienced in neuroimaging techniques that allow easy identification of lesions in the subdural space. (2)

For the neurosurgeon, the $\mathrm{CSH}$ is a condition of daily management, obtaining surgical resolution due to the relatively good performance in most cases. But beneath its apparent "goodness", mortality in patients with $\mathrm{CSH}$ is usually between $0.5 \%$ and $8 \%$, some reports reach a mortality of $20 \%$.

A better understanding of the pathophysiology of this entity, identifying risk factors, advances in diagnosis and advances in treatment options have significantly improved the prognosis. $(3,4)$ However, this disease in young is unusual; we present a case of a young male patient with no trauma history who developed spontaneous CSH. 


\section{Clinical case}

A 16-year-old male patient, without any relevant clinical record, presented holocraneal headache for 2 months, and was transferred from a local hospital that does not have access to neurosurgical care. The patient was admitted to our emergency department with a Glasgow Coma Scale (GCS) score of 14 associated with right hemiparesis with motor strength grade 3 .

Brain Computed tomography (CT) and magnetic resonance imaging (MRI) documented a large subdural collection in the left hemisphere. (Figure 1). We decided to perform surgical evacuation of subdural hematoma with placement of a closed drainage system. The postoperative period was unremarkable at 2 months follow-up, the patient was in GCS 15. Postoperative TC documented brain re-expansion and resolution of the subdural collection (Figure 2).

\section{Discusion}

\section{Physiopathology}

$\mathrm{CSH}$ is a collection of encapsulated blood, situated below the dura, mainly characterized by the presence of a membrane composed of two layers, an outer and an inner layer. The outer layer undergoes a process which leads to a meningeal reaction due to hemorrhage, which involved blood vessels, smooth muscle cells, eosinophils, erythrocytes, and the collagen fibers subsequently it continuous with neovascularization in large sinusoids with fragile thin walls, with spaces between which passage of erythrocytes and blood plasma is allowed. So it behaves as a semipermeable structure that allows the entry of liquid, favoring the increase of the volume of hematoma.

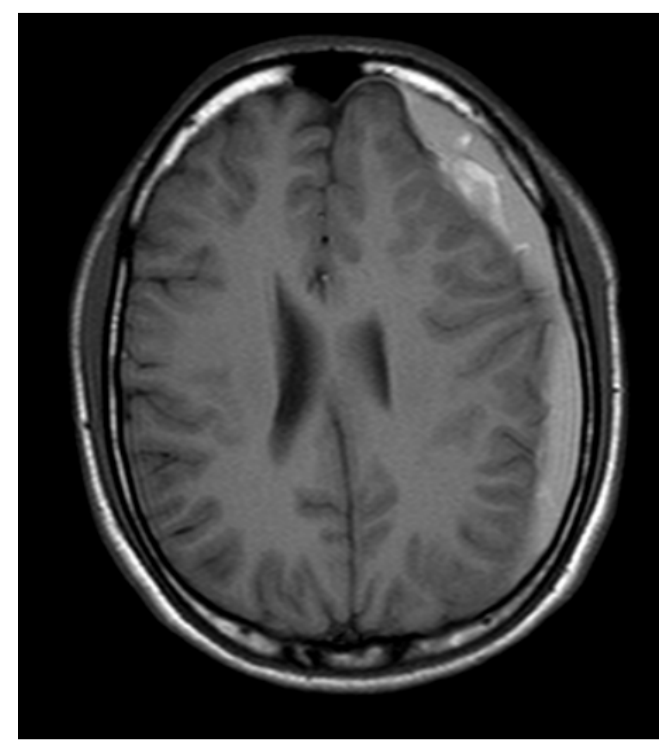

Figure 1 - Brain MRI; axial sections showing the presence of CSH right frontoparietal convexity, determining a displacement of the middle line, without subfalcine hernia

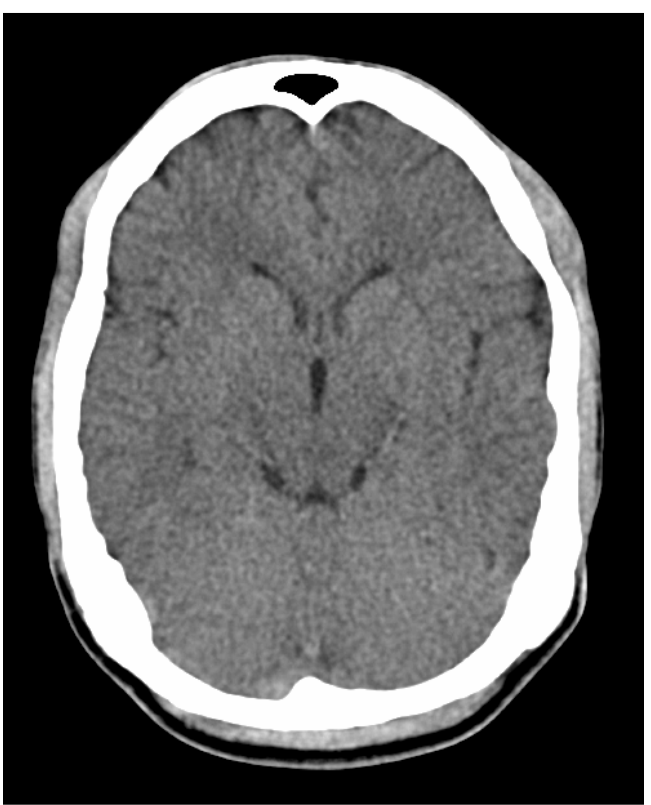

Figure 2 - Postoperative TC at 60 days, showing brain re-expansion without any residual subdural collection 
DOI: 10.2478/romneu-2014-0030

It has been determined that the two membranes surrounding the hematoma are originated between the first and the fourth week of the first collection of blood. This is followed by neocapilar growth and liquefaction of the hematoma associated with enzymatic fibrinolysis. Furthermore it has been established that in the hematoma outer membrane occur local fibrinolysis, with low levels of fibrinogen and plasminogen. Degradation products of fibrin which ultimately inhibit the hemostatic cascade are also increased.

\section{Factors associated}

In most cases, $\mathrm{SDH}$ is a complication of traumatic brain injury, been rare the nontraumatic causes. At younger ages (child or adolescent), spontaneous chronic SDH is very unusual. The estimated incidence varies between 1.72 SDH, and 14.1 cases per 100,000 inhabitants / year, reaching 7.35 to 10.5 in the age group 70-79 years. (5-7) $83 \%$ occur in patients older than 40 years.

Several factors have been cited as causes, including head trauma, chronic alcoholism and anticoagulation. It has been suggested that a secondary alcohol leads to chronic liver damage coagulopathy and the probable risk of cranial trauma. In the literature it is present between 10 and $50 \%$ of cases. Other described causes are primary tumors, metastases or vascular malformations, among others.

\section{Reports}

Spontaneous chronic SDH is a rare entity reported. Carvalho et al.(4) in a review of the literature searching for spontaneous $\mathrm{SDH}$, found the case of a 22-year-old patient who complained of persistent headaches and was neurologically intact on examination. Cranial $\mathrm{CT}$ revealed the presence of a right-sided chronic subdural hematoma; the evaluation was followed by MRI plus angiogram, aiming to rule out the presence of any vascular abnormality. As surgical treatment, a burrhole craniostomy procedure was used, resulting in resolution of symptoms.

Wang et al. (8) reported the case of SDH in a healthy 14-year-old girl who presented with severe headache following blurring of vision two weeks before the presentation without any history of head injury. CT and MRI demonstrated a chronic SDH. The cause of the hematoma was not established. As in the case found by Carvalho et al, after performing burr hole drainage of the hematoma, the patient made an uneventful recovery.(8)

Brennan et al. (9) present an unusual case of a 37-year-old healthy young male, who developed a spontaneous SDH. His clinical manifestations were headache was followed by blurring of vision and left upper limb symptoms. The diagnosis was made from a CT scan. Symptoms resolved with surgical decompression.(9) This patient was a saxophonist, in who is believed as cause of the hematoma the increase in the venous pressure, as result of Valsalva's maneuver during music performance.

\section{Clinical course}

Chronic SDH typically occurs in individuals older than 60 years, men, alcoholics or with blood dyscrasias and 
frequent falls, complaining of a progressive clinical syndrome characterized by motor deficits, adding to signs and symptoms of intracranial hypertension.

The course of chronic subdural hematoma is slowly progressive, allowing its accommodation around the brain and thereby prevents the sudden development of intracranial hypertension. It is recommended to start research through brain CT in all patients with brain qualitative disorder of consciousness, no matter if is an elderly patient. It can also present as a transient neurological deficit, headache, slurred speech, hemiparesis, seizures, etc. In the young patient the main symptoms are headache $(59.5 \%)$ and seizures (21.4\%), alterations in conscious level are marked in younger rather than elderly patients. (10)

\section{Diagnosis and management}

It is extremely important to establish an accurate diagnosis, because it can be misinterpreted as ischemic event and be treated as such (oral anticoagulation or antiplatelet therapy) which is quite risky. Simple Brain TC is the current imagenology aid choice for the diagnosis of this entity. Multiple treatments have been proposed, from mere observation, use of drugs (tranexamic acid, corticosteroids) and the different types of surgery. Given the pathophysiology possibly the best option is the evacuation of the collection.

Conservative treatment is based on the osmotic theory of the formation and growth of chronic SDH by parenteral administration of hyperosmolar substances, which tend to reduce the absorption and volume of hematoma.

\section{What happen in young patients?}

There are very few publications about $\mathrm{SDH}$ in the younger population (10-12) because in this age group is not common to see 2 of the main predisposing factors for its development: brain atrophy and use of drugs that interfere with hemostasis. In young people there are a number of factors that we do not see in other age groups, among which: the coagulation disorders such as thrombocytopenic purpura (13) coagulation factors deficits (14) or hematological abnormalities from oncological nature.

According to Gelabert-González et al. (15), in patients lesser than 40 years old, the mean age at diagnosis is $29.3 \pm 8.9$ years (range: 4 to 39 years). Some factors that facilitate the development of $\mathrm{SCH}$ in young patients including arachnoid cysts, $(17,18)$ intracranial hypotension (e.g. ventriculoperitoneal shunt or traumatic/spontaneous spinal fistula) and the consumption of anabolic drugs (e.g. weightlifting). Hesselbrock et al (16) review 21 patients with nontraumatic SDH, they found as risk factors: arterial hypertension, vascular malformations, neoplasia such as haematological malignancies causing thrombocytopaenia, solid tumour, dural metastases, infection, hypervitaminosis, coagulopathy and alcoholism.

Regarding our case, it is proposed that episodes of sudden increase in venous pressure can lead to subdural bleeding. This can happen during Valsalva maneuvers as previously mentioned. In young patients taking anabolic drugs, it is believed that the subdural 
DOI: 10.2478/romneu-2014-0030

hemorrhage is caused by vascular remodeling. Our patient did not use steroids or recreational drugs, which also have been associated with subdural hematomas. $(8,9)$

Spontaneous chronic SDH is a rare entity, which treated by conventional neurosurgical management produces offers satisfactory results.

\section{Correspondence:}

Luis Rafael Moscote, MD;

e-mail:mineurocirujano@aol.com

\section{References}

1. Lo W-L, Lee T-C, Fang P-S, Huang Y-H. Chronic subdural hematoma in patients under age 65 years: A comparative study of age cohort. Formos J Surg [Internet]. 2013 Feb [cited 2014 Mar 21];46(1):10-4. Available from:

http://linkinghub.elsevier.com/retrieve/pii/S1682606X12 001193

2. Arpino L, Gravina M, Basile D, Franco A. Spontaneous chronic subdural hematoma in a young adult. $J$ Neurosurg Sci [Internet]. 2009 Jun [cited 2014 Mar 21];53(2):55-7. Available from:

http://www.ncbi.nlm.nih.gov/pubmed/19546844

3. Lee K-S. Natural history of chronic subdural haematoma. Brain Inj [Internet]. 2004 Apr [cited 2014 Mar 21];18(4):351-8. Available from:

http://www.ncbi.nlm.nih.gov/pubmed/14742149

4. De Carvalho D, Almenawer S, Lozej M, Noble H, Murty NK. Spontaneous chronic subdural hematoma in a 22-year-old healthy woman. World Neurosurg [Internet]. 2013 Nov [cited 2014 Mar 19];80(5):654.e911. Available from: http://www.ncbi.nlm.nih.gov/pubmed/23182734 5. Foelholm R, Waltimo O. Epidemiology of chronic subdural haematoma. Acta Neurochir [Internet]. 1975 Jan [cited 2014 Mar 19];32(3-4):247-50. Available from: http://www.ncbi.nlm.nih.gov/pubmed/1225014

6. Cousseau DH, Echevarría Martín G, Gaspari M, Gonorazky SE. [Chronic and subacute subdural haematoma. An epidemiological study in a captive population]. Rev Neurol [Internet]. 2001 [cited 2014 Mar 19];32(9):821-4. Available from: http://www.ncbi.nlm.nih.gov/pubmed/11424031

7. Ducruet AF, Grobelny BT, Zacharia BE, Hickman ZL, DeRosa PL, Anderson K, et al. The surgical management of chronic subdural hematoma. Neurosurg Rev [Internet]. 2012 Apr [cited 2014 Mar 19];35(2):155-69; discussion 169 Available from: http://www.ncbi.nlm.nih.gov/pubmed/21909694

8. Wang HS, Kim SW, Kim SH. Spontaneous chronic subdural hematoma in an adolescent girl. J Korean Neurosurg Soc [Internet]. 2013 Mar [cited 2014 Mar 21];53(3):201-3. Available from:

http://www.pubmedcentral.nih.gov/articlerender.fcgi?ar tid $=3638278 \&$ tool $=$ pmcentrez\&rendertype $=$ abstract 9. Brennan PM, Fuller E, Shanmuganathan M, Keston P, Fouyas I. Spontaneous subdural haematoma in a healthy young male. BMJ Case Rep [Internet]. 2011 Jan [cited 2014 Mar 21];2011. Available from:

http://www.pubmedcentral.nih.gov/articlerender.fcgi?ar tid $=3149419 \&$ tool $=$ pmcentrez\&rendertype $=$ abstract 10. Liliang P-C, Tsai Y-D, Liang C-L, Lee T-C, Chen H-J. Chronic subdural haematoma in young and extremely aged adults: a comparative study of two age groups. Injury [Internet]. 2002 May [cited 2014 Mar 19];33(4):345-8. Available from:

http://www.ncbi.nlm.nih.gov/pubmed/12091031

11. Aoki N. Chronic subdural hematoma in infancy. Clinical analysis of 30 cases in the CT era. J Neurosurg [Internet]. 1990 Aug [cited 2014 Mar 19];73(2):201-5. Available from:

http://www.ncbi.nlm.nih.gov/pubmed/2366077

12. Mauer UM, Kunz U. [Chronic subdural hematoma in patients under 35 years of age]. Nervenarzt [Internet]. 2007 Feb [cited 2014 Mar 19];78(2):177-80. Available from: http://www.ncbi.nlm.nih.gov/pubmed/17245586 13. Seçkin H, Kazanci A, Yigitkanli K, Simsek S, Kars HZ. Chronic subdural hematoma in patients with idiopathic thrombocytopenic purpura: A case report and review of the literature. Surg Neurol [Internet]. 2006 Oct [cited 2014 Mar 21];66(4):411-4; discussion 414. Available from: http://www.ncbi.nlm.nih.gov/pubmed/17015125 14. Albanese A, Tuttolomondo A, Anile C, Sabatino G, Pompucci A, Pinto A, et al. Spontaneous chronic subdural hematomas in young adults with a deficiency in coagulation factor XIII. Report of three cases. J Neurosurg [Internet]. 2005 Jun [cited 2014 Mar 21];102(6):1130-2. Available from:

http://www.ncbi.nlm.nih.gov/pubmed/16028774 15. Gelabert-González M, Frieiro-Dantas C, SerramitoGarcía R, Díaz-Cabanas L, Aran-Echabe E, Rico-Cotelo 
$\mathrm{M}$, et al. [Chronic subdural hematoma in young patients]. Neurocirugia [Internet]. 2013 Mar [cited 2014 Mar 19];24(2):63-9. Available from:

http://www.ncbi.nlm.nih.gov/pubmed/23158924

16. Hesselbrock R, Sawaya R, Means ED. Acute spontaneous subdural hematoma. Surg Neurol [Internet]. 1984 Apr [cited 2014 Mar 22];21(4):363-6. Available from: http://www.ncbi.nlm.nih.gov/pubmed/6701770 17. Chan J-Y, Huang C-T, Liu Y-K, Lin C-P, Huang J-S. Chronic subdural hematoma associated with arachnoid cyst in young adults: a case report. Kaohsiung J Med Sci
[Internet]. 2008 Jan [cited 2014 Mar 19];24(1):41-4. Available from:

http://www.ncbi.nlm.nih.gov/pubmed/18218569

18. Mori K, Yamamoto T, Horinaka N, Maeda M. Arachnoid cyst is a risk factor for chronic subdural hematoma in juveniles: twelve cases of chronic subdural hematoma associated with arachnoid cyst. J Neurotrauma [Internet]. 2002 Sep [cited 2014 Mar 21];19(9):1017-27. Available from:

http://www.ncbi.nlm.nih.gov/pubmed/12482115 